\title{
Projeto de Extensão de Iniciação à Programação: uma experiência com jovens do agreste alagoano
}

\author{
José Bruno da Silva Santos ${ }^{1}$, Emerson Ferreira de Araújo Lima ${ }^{1}$
}

\author{
${ }^{1}$ Campus Palmeira dos Índios - Instituto Federal de Alagoas (IFAL) \\ Av. Alagoas, s/n - Palmeira de Fora, Palmeira dos Índios - AL, 57608-180. \\ jbsslealuno.ifal.edu.br, emerson@ifal.edu.br
}

\begin{abstract}
This article aims to report the experience obtained in the Program of Initiation to Programming (PIP), an extension action linked to the Federal Institute of Alagoas - IFAL Campus Palmeira dos Indios, targeting young people from the Antonio Caetano de Souza Municipal School and Association Home and Family located in the municipality of igaci, belonging to the agreste alagoano. The Project aimed to teach programming in a simple way of understanding, in addition to digitally including its participants providing new experiences and developing skills in the area of computing.

Resumo. $O$ presente artigo tem por objetivo relatar a experiência obtida no Projeto de Iniciação à Programação (PIP), ação de extensão vinculada ao Instituto Federal de Alagoas - IFAL Campus Palmeira dos Índios, tendo como público alvo jovens da Escola Municipal Antonio Caetano de Souza e Associação Lar e Família situados no município de igaci, pertencente ao agreste alagoano. O Projeto teve como objetivo o ensino de programação de uma forma simples de entendimento, além de incluir digitalmente seus participantes proporcionando novas experiências e desenvolvendo habilidades na área de computação.
\end{abstract}

\section{Introdução}

É fundamental a introdução de conceitos de Ciência da Computação na Educação Básica como forma de aprimorar o raciocínio computacional das crianças, pelo seu caráter transversal a todas as ciências [Nunes 2011]. O pensamento computacional e o raciocínio lógico deveriam ser ensinados desde cedo, já que aumentam a capacidade de dedução e conclusão de problemas [Sica 2008].

Desta forma torna-se essencial investir em ações que disseminem o ensino de computação, especialmente em programação como forma de trazer novas oportunidades sociais e econômicas ao público atendido que em sua maioria são alunos da rede pública de ensino, uma vez que escolas particulares já adotam aulas na área de computação em seus componentes curriculares. A aprendizagem da informática e o acesso às novas linguagens de comunicação e informação não só possibilitam oportunidades econômicas, de geração de renda, como também representam um importante capital social [Baggio 2000].

Considerando a importância ressaltada sobre os aspectos benéficos do ensino da computação as crianças do ensino fundamental, este artigo apresenta a experiência obtida no projeto de extensão vinculado ao Instituto Federal de Alagoas (IFAL) intitulado: Iniciação à Programação - (PIP) que foi realizado no laboratório de informática da Associação Lar e Família no período de abril a novembro de 2019. 
O projeto de extensão teve como finalidade o ensino introdutório a programação com a linguagem de programação python e outras atividades relacionadas à tecnologia, proporcionando novas experiências aos alunos do $8^{\circ}$ e $9^{\circ}$ ano da Escola Municipal Antonio Caetano de Souza, e participantes da Associação Lar e Família, ambos localizados no município de Igaci interior do agreste alagoano.

\section{Extensão universitária}

A Extensão Universitária é o processo educativo, cultural e científico que articula o Ensino e a Pesquisa de forma indissociável e viabiliza a relação transformadora entre Universidade e Sociedade [Fórum de Pró-Reitores de Extensão das Universidades Públicas Brasileiras 2000/2001]. Os projetos de extensão são de enorme importância para a sociedade, uma vez que através deles é possível compartilhar o conhecimento obtido durante a graduação nas instituições de ensinos, levando esses conhecimentos para fora dos muros da universidade a favor da comunidade beneficiada pela ação como forma de expansão do conhecimento.

Em [Vasconcelos 1996] é apresentado que ensino, pesquisa e extensão representam, com igualdade de importância, o tripé que dá sustentação a qualquer universidade que se pretenda manter como tal. Já para [Silva 1996] o processo de extensão é descrito como oportunidade para levar a universidade até a comunidade, assim como os conhecimentos que ela possui, os novos conhecimentos que produz com a pesquisa e que normalmente divulga com o ensino.

Em [Silva 1996] é salientado o fato de que as atividades de extensão quando bem planejadas, estruturadas e executadas permitem à universidade socializar e democratizar os conhecimentos dos mais diversos cursos e áreas, além de preparar seus profissionais não somente com a estratégia do ensino-transmissão, mas complementando a formação com a estratégia do ensino-aplicação.

\subsection{Trabalhos Relacionados}

Vários Projetos em computação têm sido realizados no Brasil nos últimos anos como forma de expandir o aprendizado na área e levar a diversos públicos temas que até então eram restritos às universidades. Tais ações em sua maioria possuem público alvo crianças e jovens menos favorecidos socialmente, dando-lhe condições de participação, possibilitando processos como a inclusão digital e programação.

Em [IFAL 2020] ele mostra que o objetivo da extensão é a troca de saberes entre os dois segmentos, onde a comunidade se beneficia com o resultado direto das atividades extensionistas, e ao mesmo tempo retroalimenta as práticas de ensino e pesquisa a partir de suas reais necessidades.

No artigo [Rodrigues 2016, 2017] é relatada as experiências de projetos de extensão no ensino de conceitos básicos de programação e programação de jogos feita com 16 alunos em cada ano de escolas da rede municipal de ensino em conjunto com o Instituto Federal de Educação, Ciência e Tecnologia de São Paulo, usando a ferramenta Scratch.

Já o programa Meninas Digitais tem como objetivo divulgar a área de Computação e suas tecnologias para despertar o interesse de meninas estudantes do 
ensino médio (nas suas diversas modalidades) e dos anos finais do ensino fundamental, para que estas conheçam melhor a área e sintam-se motivadas em seguir uma carreira em Computação [SBC, 2015].

Uma experiência interessante relatada em [Araújo 2018] sobre a escola de verão de programação que tinha o objetivo de oferecer um ambiente divertido e interativo de ensino de programação durante as férias escolares para crianças.

O projeto de extensão de Iniciação a Programação se diferencia dos demais em relação ao tempo de execução da proposta, já que em sua maioria os projetos são de pequena duração tendo em vista que o PIP possui uma carga horária de 400h, além da metodologia aplicada, nosso intuito inicialmente era a inclusão digital dos participantes e posteriormente o ensino de programação em si. Outros benefícios ligados ao domínio da programação e ajudar a organizar ideias, pensamentos e objetivos de vida [Wing 2006].

Desta forma, será relatado toda a experiência obtida durante todo o projeto de extensão com os alunos do $8^{\circ}$ e $9^{\circ}$ anos do ensino fundamental II da escola municipal Antonio Caetano de Souza e participantes da Associação Lar e Família no ano de 2019. O objetivo geral empregado a esse projeto resultou na disseminação do conhecimento em programação, além de promover a inclusão digital de adolescentes a fim de despertar nos participantes o interesse pela informática.

\section{O Projeto}

O projeto de Iniciação a Programação foi uma ação de extensão vinculada ao IFAL que visava levar aos participantes inclusão digital e uma breve introdução a história da computação, juntamente com a iniciação à programação, utilizando-se da linguagem de programação python de modo que os participantes pudessem obter conhecimentos dos assuntos. A ação de extensão foi realizado com encontros presenciais pela manhã no período de abril a novembro de 2019 na Associação Lar e Família, onde há um laboratório de informática. Neste foram ministradas aulas práticas e teóricas sobre o tema exposto para os participantes que foram beneficiados pela ação. O objetivo geral da ação era que a partir dos conhecimentos obtidos os participantes fossem capazes de construir algoritmos para a resolução de alguns problemas, sendo eles do cotidiano ou não, além dos objetivos específicos mencionados a seguir:

1. Promover a inclusão digital, como uma forma de adquirir conhecimentos e um modo de obter novas oportunidades na área;

2. Mostrar aos alunos uma nova forma de utilizar a tecnologia e ter esta mesma como ferramenta de avanço;

3. Ensinar programação de forma fácil de compreensão;

4. Mostrar caminhos de continuar aprendendo sobre a tecnologia mesmo depois que as atividades da ação finalizarem.

Inicialmente o Projeto de Iniciação a Programação (PIP) contava com a participação de 20 estudantes de ambos os sexos, com faixa etária entre 12 a 20 anos, 16 eram alunos do ensino fundamental II pertencentes à rede pública municipal de ensino do povoado Novo Rio, já os outros 4 faziam parte da Associação Lar e Família, ambos localizado no município de Igaci no agreste do interior alagoano. Também foi 
verificado que nenhum dos participantes que estavam ali obtinham algum conhecimento referente aos assuntos de computação que seriam abordados no projeto ou teriam participado de alguma ação referente a área.

\section{Metodologia}

O PIP foi subdividido em etapas como apresentado na Tabela 1 é descrito a seguir:

Etapa 1: início da ação de extensão, manutenção e instalação das aplicações necessárias nos computadores do laboratório, divulgação e seleção dos participantes, criação de material para uso na ação.

- Foi realizado nos computadores do laboratório devidas manutenções de hardware e software e instalações das aplicações necessárias para a realização do curso.

- Divulgação do curso aos alunos da escola Antonio Caetano de Souza e aos participantes da Lar e Família posteriormente fazendo a seleção dos participantes, obedecendo alguns critérios propostos pela equipe de execução da ação, que seriam beneficiados pela projeto.

- Criação de materiais didáticos tais como slides, atividades de fixação além de material complementares como livros, vídeoaula, ambientes virtuais de ensino, para atender a demanda dos participantes, além das práticas em laboratório durante a ação.

Etapa 2: histórico da computação, hardware e software.

- No início das aulas foi abordada a história da computação, como meio de levar aos participantes uma noção inicial do funcionamento e evolução da computação através dos tempos.

- Conceitos de hardware e software tendo como intuito o levar aos participantes a diferença eles e a compreensão de como é efetuada a comunicação de ambos.

- Atividades de fixação.

- Aplicação de prova com os conteúdos vistos como forma de verificação do aprendizado.

Etapa 3: lógica como forma de pensar, lógica computacional.

- Iniciamos o assunto central da ação, que é a programação, no ensino da lógica como forma de pensar, e posteriormente lógica computacional, mostrando os principais conceitos que seriam aplicados a cada vez que o curso tivesse sua progressão.

- Atividades de fixação.

Etapa 4: linguagem de programação, diagrama de blocos e conceitos iniciais programação.

- Histórico e introdução a linguagens de programação, mostrando seus diferentes tipos e diferenças entre linguagens de baixo e alto nível e diferenças entre interpretadas e compiladas.

- Python: histórico da linguagem e aplicabilidade nos estudos em programação. 
- Ensino sobre a estrutura de um algoritmo utilizando diagrama de blocos como forma de melhorar a compreensão.

- Ensino dos conceitos iniciais de programação: variáveis e seus tipos, impressão de dados na tela, regras de uso e operações matemáticas.

- Atividades de fixação.

- Desenvolvimento de trabalho com os assuntos da etapa 3 e 4 como forma de verificação do aprendizado.

Etapa 5: Entrada e saída de dados e seus tipos, operadores relacionais e lógicos e desenvolvimento do relatório parcial.

- Ensino das formas de entrada e saída de dados e seus principais tipos.

- Ensino dos operadores relacionais e lógicos.

- Atividades de fixação.

Etapa 6: Estruturas de seleção, estruturas de repetição.

- Introdução a estruturas de seleção e seus tipos.

- Introdução a estruturas de repetição.

- Atividades de fixação.

- Desenvolvimento de trabalho prático com os assuntos da etapa 5 e 6 como forma de verificação do aprendizado.

Etapa 7: Apresentação da proposta de projeto, desenvolvimento do projeto.

- Apresentação da proposta de possíveis aplicações aos participantes para desenvolvimento, momento em que foram formadas equipes de 4 alunos como forma de pôr em prática tais conhecimentos adquiridos durante a ação de extensão.

- Desenvolvimento do projetos pelas equipes.

Etapa 8: Apresentações do projeto, orientações para continuar o aprendizado, finalização da ação de extensão.

- Apresentação das aplicações desenvolvidas pelas equipes.

- Orientações aos participantes sobre a continuação do aprendizado após a finalização do projeto.

- Reunião com a escola para avaliação do projeto.

- Finalização da ação de extensão.

Por fim, foi realizada uma roda de conversa entre os participantes após a visita ao prédio do IFAL, como forma de levar incentivo e motivação para continuar os estudos na área além da troca de experiência entre os participantes. Durante a conversa, os participantes pontuaram sobre suas experiências com o curso e o que aplicou-se no cotidiano de cada um, a equipe executora da ação acrescentou em levar incentivo aos participantes prestarem o exame de seleção do IFAL. 


\begin{tabular}{|c|c|c|c|c|c|c|c|c|}
\hline Etapas & Abr & Maio & Jun & Jul & Ago & Set & Out & Nov \\
\hline Etapa 1 & $\mathrm{X}$ & & & & & & & \\
\hline Etapa 2 & & $\mathrm{x}$ & & & & & & \\
\hline Etapa 3 & & $\mathrm{x}$ & & & & & & \\
\hline Etapa 4 & & & $\mathrm{x}$ & & & & & \\
\hline Etapa 5 & & & & $\mathrm{x}$ & & & & \\
\hline Etapa 6 & & & & & $\mathrm{x}$ & $\mathrm{x}$ & & \\
\hline Etapa 7 & & & & & & & $\mathrm{x}$ & \\
\hline Etapa 8 & & & & & & & & $\mathrm{x}$ \\
\hline
\end{tabular}

Tabela 1. Cronograma da execução das etapas mensais desenvolvidas no projeto.

\section{Resultados e Discussões}

Durante todo o período de execução da ação houve uma grande troca de conhecimento entre os membros da equipe da ação com os participantes, os resultados obtidos foram bastante satisfatórios em diversos aspectos, que serão apresentados posteriormente.

O projeto inicialmente contava com a participação de 20 alunos no total, mas houveram algumas desistências. Contudo, a evasão que o curso teve já era prevista desde a elaboração da proposta para submissão ao IFAL, que também era a instituição financiadora do projeto. Ao fim da ação 16 dos 20 participantes concluíram com êxito sua participação no projeto, como mostrado na Gráfico 1.

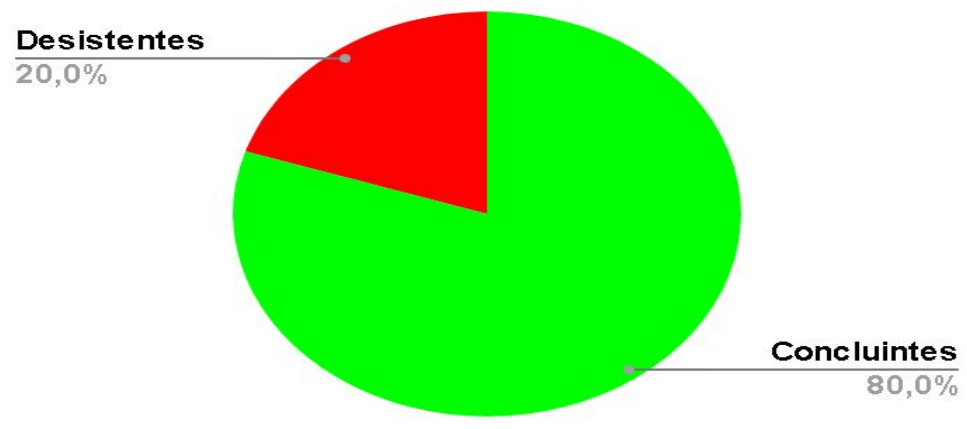

Grafico 1. Percentual de evasão do curso.

\subsection{Resultados Quantitativos}

Durante toda a ação foram feitas algumas avaliações, tendo em vista o nível de construção do conhecimento dos participantes, ao final foram totalizados 4 avaliações sendo elas: 2 trabalhos sendo um prático e outro teórico, 1 prova com questões de múltipla escolha e 1 projeto mostrados nas Figuras 1,2 e 3 respectivamente, como forma de verificação do nível de aprendizado. 


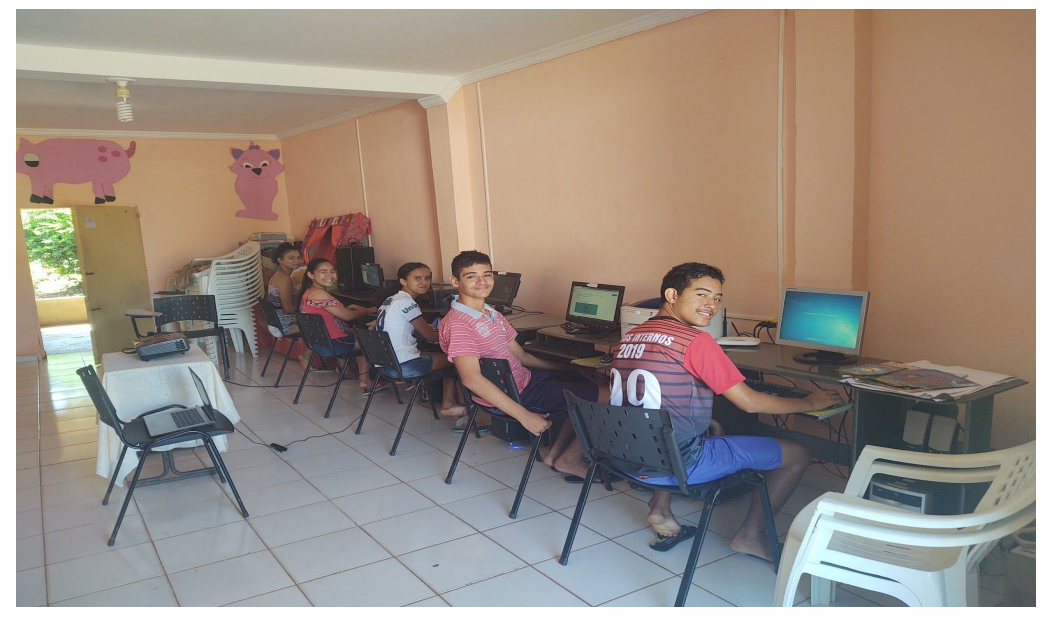

Figura 1. Participantes durante o desenvolvimento do trabalho prático.

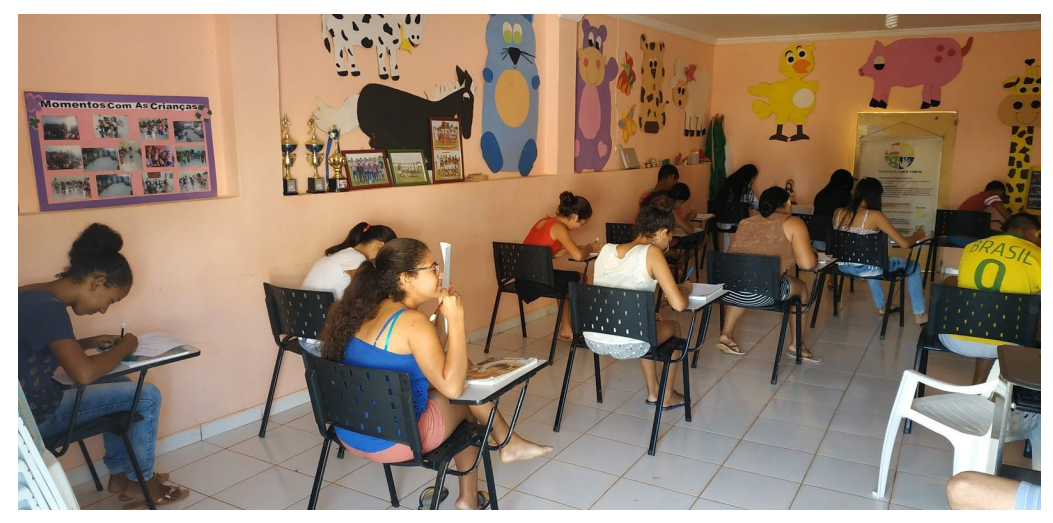

Figura 2. Participantes durante a aplicação da prova.

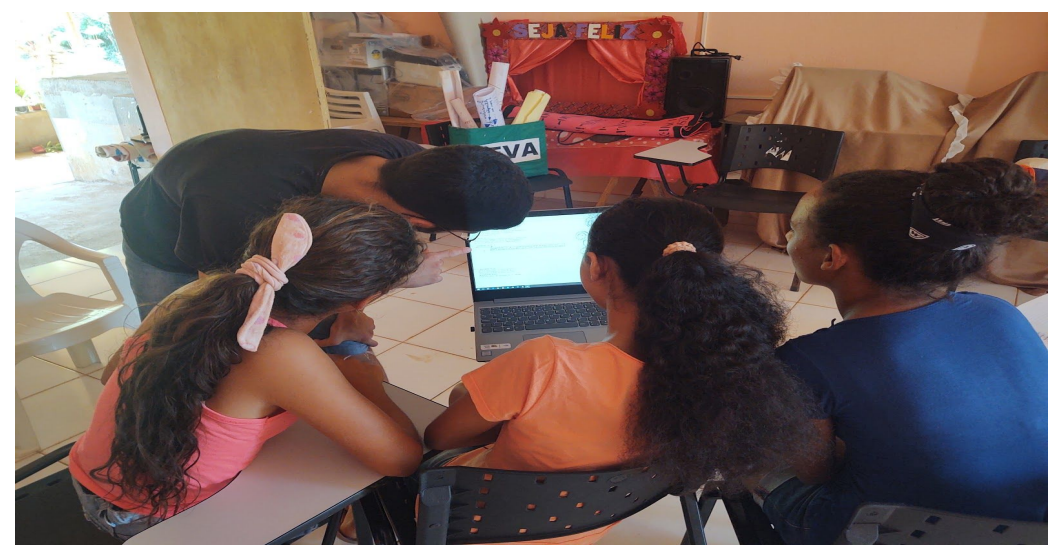

Figura 3. Participantes desenvolvendo os Projetos.

A média geral das avaliações da turma ao final da ação foi de 9.12 a partir do cálculo da média individual de cada aluno em cada avaliação, juntamente com o cálculo da média de toda a turma. Em virtude, foi constatado resultados satisfatórios, uma vez que a média foi bem superior à média padrão, que é de valor 6 .

Por fim, foi realizada uma pesquisa de satisfação do curso, em que os participantes avaliaram o curso sobre as devidas considerações: Muito Satisfeito, Satisfeito, Regular, Insatisfeito e Muito Insatisfeito. Considerações onde 14 
participantes avaliaram como "Muito Satisfeitos", formando um percentual de 87,5 \% os outros 2 participantes avaliaram como "Satisfeito" formando um percentual de 12,5 $\%$, somando os 2 percentuais totalizando $100 \%$ das avaliações como mostrado no Gráfico 2 e dadas em relação ao nível de satisfação dos participantes referentes ao projeto de extensão.

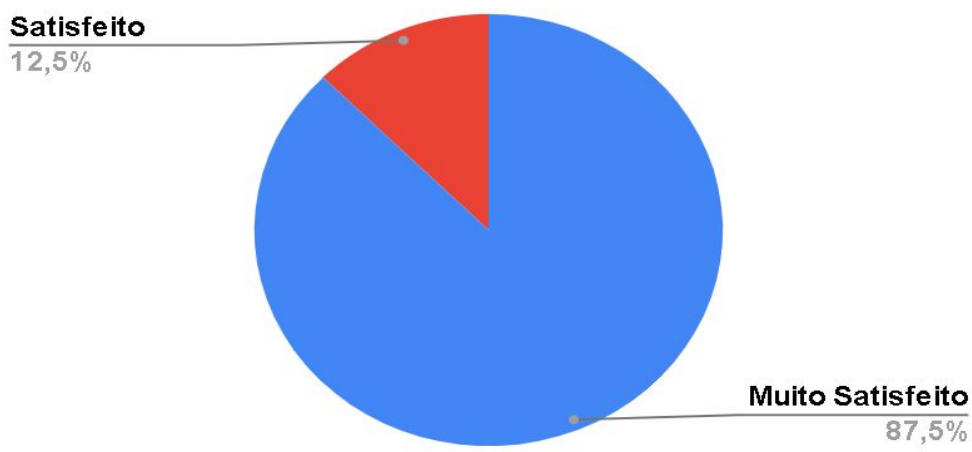

Gráfico 2. Percentual da pesquisa do nível de satisfação dos participantes em relação ao projeto PIP.

\subsection{Resultados Qualitativos}

Pode-se notar que houve uma grande contribuição na vida dos participantes, levando a inclusão digital e a introdução a programação a eles e abrindo um enorme leque de oportunidades e experiências. Todos os conceitos preestabelecidos no cronograma foram ministrados e a cada aula prática ou teórica era notável o interesse cada vez maior por parte dos participantes, alguns se destacaram inicialmente, conseguindo absorver o assunto rapidamente e muitas vezes ajudando o colega que possuía dificuldade fora dos momentos presenciais da ação de extensão.

Durante a roda de conversa no último encontro do projeto foi perguntado o que acharam do projeto e houve um feedback positivo, sendo mencionado no relatório final da ação como mostrado em [Santos et al. 2019 ]:

Relato 1: "O curso de programação para mim ajudou bastante, aprendi coisas que nunca imaginei, como por exemplo que uma calculadora é um computador. Aprendi também sobre a história da computação e como funcionavam as primeiras máquinas programadas, tenho certeza que graças ao curso irei me destacar em alguma área que resolver seguir. Além de conseguir entender como grandes empresas conseguem programar seus computadores e o quão interessante é trabalhar com isso."

Relato 2: "Eu achei que foi um curso muito bom, e que aprendi várias coisas legais e que é sempre bom as pessoas tentarem fazer um curso. Principalmente o que vc está fazendo, tá dando uma oportunidade para aqueles que não tem condições de fazer. Eu gostei de verdade mesmo, o melhor curso que eu já fiz." Relato 3: "Eu aprendi sobre os códigos, sobre como fazer calculadoras matemáticas e sim me ajudou na escola bastante no aprendizado ou melhor em matemática, uma matéria que pede muito cálculos.”.

A partir dos relatos obtidos podemos ver que a tecnologia deve ser disseminada em todas as partes onde se torna indispensável o seu aprendizado, pois vivermos em um 
mundo que está em evolução diariamente. Além de mostrar formas de continuar seu aprendizado na área a fim de construir um interesse maior pela área da informática.

\subsection{Dificuldades Encontradas}

O laboratório não comportava todos os participantes ao mesmo tempo, sendo necessário a divisão da turma em duas na maioria dos encontros, em relação as aulas eram práticas, devido a baixa quantidade de computadores que foi o principal motivo. Alguns Participantes faltavam muito em determinadas épocas do curso, visto que necessitavam de autorização prévia dos pais para a ação de extensão, muitas vezes precisavam ajudar em afazeres domésticos ou até mesmo do campo.

\subsection{Ajustes}

Foram ministradas aulas extras para os participantes que possuíam muitas faltas como forma de equilibrar o ensino e o aprendizado, por fim conseguindo alcançar um nível satisfatório em relação a turma em geral.

\section{Considerações Finais}

As experiências obtidas pela equipe de execução do projeto de extensão, foi considerada bastante enriquecedora do ponto de vista em que a equipe quanto os participantes superaram diversos desafios durante a execução do projeto indo de laboratórios com poucas máquinas para a execução das aulas práticas, alguns participantes tinham que faltar algumas aulas para ajudar os pais em serviços domésticos e do campo. Contudo durante toda a execução do projeto mostraram que é possível superar desafios e inserir o ensino da programação para estudantes do ensino fundamental, aliando conhecimentos teóricos e práticos em aplicações no mundo real, já que tais ações não fazem parte do cotidiano escolar dos participantes inseridos no projeto de extensão.

Após análise dos resultados obtidos, foi constatado que obtivemos resultados bastantes satisfatórios apesar da evasão que somou um percentual de $20 \%$ do público inicial da ação, além de somar um grande impacto junto à comunidade, assim trazendo novos conhecimentos e oportunidades como forma de difundir a computação em locais com acesso mais restrito a tais conhecimentos. A direção de ambas as instituições atendidas pelo projeto expuseram sua satisfação com a atividade desenvolvida com seus alunos além de salientar um crescimento significativo no desempenho dos estudantes nos estudos durante a execução da ação.

O método utilizado neste projeto de extensão, visa contribuir para futuras ações de extensão no ensino de programação em escolas públicas, como forma de motivar a disseminação de conhecimento em ciência da computação. Deste modo despertando nos participantes das ações habilidades para uso em sua carreira acadêmica e em olimpíadas, mais especificamente a Olimpíada Brasileira de Informática - OBI como forma de descobrir novos talentos na área de computação.

\section{References}

VASCONCELOS, M. L. M. C. (1996). A formação do professor de $3^{\circ}$ Grau. São Paulo: Pioneira, p. 8, 
SILVA, Oberdan Dias da. (1996).O que é extensão universitária?. Disponível em: $<$ https://www.ecientificocultural.com/ECC3/oberdan9.htm>Acesso em: 25 de maio de 2020.

Fórum de Pró-Reitores de Extensão das Universidades Públicas Brasileiras. (2000 / 2001). Plano Nacional de Extensão Universitária - Edição Atualizada. Fórum de Pró-Reitores de Extensão das Universidades Públicas Brasileiras e SESu / MEC, Brasília.

SICA, Carlos. (2008). Ciência da Computação no Ensino Básico e Médio. Disponível em:<http://www.odiario.com/blogs/carlossica/2011/10/07/ciencia-da-computacao-no ensino-medio/ > Acesso em: 29 de maio de 2020.

Nunes, Daltro José. (2011). Ciência da Computação na Educação Básica. Disponível em: <https://adufrgs.org.br/artigos/ciencia-da-computacao-na-educacao-basica/> Acesso em: 29 de maio 2020.

BAGGIO, R. (2000). A sociedade da informação e a infoexclusão. Ciência da Informação. $\quad$ v. $29 . \quad$ n. 2, p. 16-21, 2000. Disponível em:<https://www.researchgate.net/publication/26349879_A_sociedade_da_informac ao_e_a_infoexclusao> Acesso em: 29 de maio 2020.

SBC. (2015). Programa Meninas Digitais. Sociedade Brasileira de Computação. Disponivel em: <http://meninas.sbc.org.br/index.php/sobre/>. Acesso em: $29 \mathrm{de}$ maio 2020.

WING, Jeannette Marie (2006). Computational thinking. Communications of ACM. v. 49, n. 3, p.33-35.

RODRIGUES, Luciene et al. (2016). Relato de experiência: curso de introdução á programação para crianças do ensino fundamental no IFSP votuporanga. Congresso Brasileiro de Informática na Educação (CBIE), XXII Workshop de Informática na Escola (WIE).

RODRIGUES, Luciene et al. (2017). Projeto de Extensão: curso de introdução a programação do ensino fundamental. Congresso Brasileiro de Informática na Educação (CBIE), XXIII Workshop de Informática na Escola (WIE).

ARAÚJO, Lara et al. (2018). Um Relato de Experiência da Escola de Verão de Programação para Crianças. Congresso Brasileiro de Informática na Educação (CBIE), XXIV Workshop de Informática na Escola (WIE)

SANTOS, José Bruno da Silva; BERNARDO, Monelly Da Silva; SOUZA, Alex De Oliveira; LIMA, Emerson Ferreira De Araújo. (2019). Projeto de Iniciação a Programação - PIP : Relatório Final. Palmeira dos Índios. p 02.

(IFAL) - Instituto Federal De Alagoas (2020). PRÓ-REITORIA de Extensão. [S. 1.], 2020. Disponível em: <https://www2.ifal.edu.br/o-ifal/extensao/> . Acesso em: 31 maio 2020. 